\title{
APPLICATION OF THE PLURIGAUSSIAN SIMULATION TECHNIQUE IN REPRODUCING LITHOFACIES WITH DOUBLE ANISOTROPY
}

\author{
ARMANDO Z. REMACRE ${ }^{1}$ \& LUÍS H. ZAPPAROLLI ${ }^{2}$
}

\begin{abstract}
Plurigaussian simulation, an improvement of truncated Gaussian method, is a new and effective procedure of reproducing complex geometrical attributes of a reservoir by means of simulating several facies with different spatial structures (anisotropies, for example) and taking into account their global proportions. The method is based on the relationship between indicator variables from facies distribution and the Gaussian random functions chosen to represent them, with the compromise of having equivalent geostatistical behavior. Geological information is incorporated to the model by the definition of the indicator variables, their truncation strategy and the facies proportions.

Two critical points arise in this methodology: the relationship between the indicator and the Gaussian variograms during the structural modeling and the correspondence between indicator and continuous variable values during the conditioning. To face them, we use iterative fitting and Gibbs sampler algorithms.

As illustration, the method was applied to a training image from a 2D geological interpretative map of the Aux Vases Zone in the Rural Hill Field - Illinois - USA, from which two sets of samples with different grid densities were extracted. Previous knowledge of the facies geometry permitted us to adopt a truncation strategy performed in both stationary and non-stationary approaches.
\end{abstract}

Keywords: plurigaussian simultaion, conditional simulation, lithofacies

INTRODUCTION An efficient exploitation of an oilfield requires a good understanding of the reservoir characteristics; mainly, on performing fluid flow simulation to get accurate oil production forecasts. For this reason, the model of quantitative reservoir characterization has to be as detailed as possible to describe properly the heterogeneities affecting fluid flow. In last decades we experiment an increase in complexity of models due to the possibility of integrate data from differently supported sources. In general, a multiple-stage approach is used to characterise a reservoir, consisting of an initial modelling of genetic or flow units of a reservoir through discrete models and, later, of simulating the spatial variation of the petrophysical parameters inside each class using continuous models. Complex patterns, such as several anisotropy axes, cannot be solved by the common methods of discrete simulations, but plurigaussian model is said to perform successfully.

The plurigaussian technique was formalised by Galli et al. (1994) and Le Loc 'h et al. (1994), and detailed by Le Loc' $h$ \& Galli (1997) and Armstrong et al. (1998). It has been applied in mining (Roth et al. 1998), geological characterisation of coastal deposits (Simon 1997, Remacre \& Simon 1998, Zapparolli 2000) and meandering channel system with crevasse splays (Armstrong \& Galli 1999).

The main purpose of this paper is to perform a heuristic approach of the plurigaussian simulation, evaluating the potential powers and the limitations of the method through its use on reproducing the facies geometry of a reservoir in a well known oilfield (Weimer et al. 1982). We focus on aspects concerning the choice of parameters and how to introduce non-stationarity to the model.

SKETCH OF PLURIGAUSSIAN METHOD The truncated
Gaussian method is based on the notion of truncation of a standard Gaussian random function by different thresholds calculated from facies proportions and was first applied to model deltaic reservoirs by Matheron et al. (1987). The covariance model of the Gaussian variable is obtained by an iterative process of inversion of the covariance model of the experimental indicator variables of the facies. The Gaussian values at the conditioning points are reconstructed through a stochastic approach. According to Galli et al. (1994), the main advantages are the theoretical consistency, speed and flexibility in incorporating external geological information like proportion curves. In contrast, the drawbacks are the facies ordering when not desired and the attribution of a single covariance model to all facies, that is, all present the same anisotropy directions.

A natural extension of that, the plurigaussian model, consists of truncating, simultaneously, two or more Gaussian variables, correlated or not, allowing the acquisition of equal number of covariance models, that describe different spatial behaviours of a facies or group of facies. The geological information is added up to the model by:

- Number of Gaussian functions;

- Correlation coefficient among them;

- Facies proportions to calculate thresholds;

- Direct and cross indicator covariances;

- Facies data at conditioning points transformed into Gaussian values;

- Truncation strategy (rock type rule)

If the facies are not stationary through the domain, one can define facies proportion curves or facies proportion matrix, obtained from the integration of external information, such as sequence stratigraphy or seismic data. The two key points of the method are

1 - Geosciences Institute, University of Campinas, UNICAMP, Caixa Postal: 6152 - CEP: 13083-970 - Campinas - SP, Brasil armando@ige.unicamp.br

2 - E\&P-BC, PETROBRAS, Brazil 
to derive Gaussian covariance models from indicator covariance models and to use an iterative algorithm of generation of Gaussian values at conditioning points respecting the spatial variation of the facies.

PRESENTATION OFEXHAUSTIVE DATA We will illustrate the method through a 2-dimensional image of the geological interpretation of the inferior portion of the Aux Vases zone in Rural Hill Field comprising the basal Mississippian Chester Series of Illinois Basin. The map was based on the analysis of wire line logs of 167 wells perforated in a $200 \mathrm{~m}$ spacing over an area about $25 \mathrm{~km}^{2}$ and of 49 cored intervals of the zone, which is positioned at an average depth of $960 \mathrm{~m}$ and with an average thickness of $12 \mathrm{~m}$.

According to the authors' interpretation (Weimer et al. 1982), there are in the area three facies types: shoreline sandstones deposited in linear build-ups parallel to the NE/SW regional trend; impermeable tidal flat and marsh deposits associated to the first; and tidal channels sandstones cutting the shoreline trend. The shoreline deposits (facies L) are composed by mature, clean, well sorted, fine grained quartz sandstones, showing horizontal laminations, rare fossil fragments and quartz overgrowth, with an average porosity of $15 \%$ and permeability inferior to $100 \mathrm{mD}$, extending for about $60 \%$ of the studied area. The tidal channel sandstones (facies M) are also mature, clean and well selected quartz sandstones, but with a very fine grain size and small to medium-scale cross-laminated beds, presenting an average porosity of $21 \%$ and permeability of hundreds of $\mathrm{mD}$, occupying over $31 \%$ of the area. Finally, the marsh and tidal flat deposits (facies S) consists of very fine sandstones interlaminated with siltstones and mudstones, characteristically not porous and not permeable, occupying the remaining $9 \%$ of the area.

The analysis of the facies proportion curves parallel to the NS direction in the 2-dimensional Aux Vases Zone geological map in Rural Hill Field (Figure 1A e B) points us to assume the nonstationarity hypothesis in at least one direction. Figure $1 \mathrm{C}$ shows the rock type rule and the global proportions of the facies. We also build a facies proportion matrix (similar to that used by Souza Jr 1997), consisting of the subdivision of the image in subsets where we can consider stationary facies proportions. We have divided the image in 36 subsets ( 6 parallel to the NS direction and 6 parallel to the EW direction), calculated the proportions inside these subsets , converted them to thresholds and plotted them in a flag form, as seen in Figure 1D. The facies M extends by the centraleastern and northwestern portion of the area and facies $S$ is concentrated in the Northwest and Southwest, while the abundant facies $L$ fills out the remaining space, locally constituting the only facies present.

The geometry of the three facies presented in the geological map shows elongated bodies in NW direction of tidal channels (facies M) that erode an association of shoreline sandstone strings of NE direction (facies L) with impermeable deposits. Although the indicator variable for facies M (Figure 2 - top left) seems to be dominated by thin clearly anisotropic structures, the presence of secondary and less continuous bodies oriented N45E causes a false isotropy as seen in variogram map and variogram of Figure 2 (top center and right). So we needed a special treatment consisting of the elimination of the tidal channels that flood in depressions parallel to the shoreline, adopted the perpendicular ones as the guidance model. After this reconstruction, we acquired a remarkable anisotropy with direction N50W as seen at bottom center and right of figure 2 .
To model them, initially we define the indicator variables for each facies, whose expectations are the facies proportions and define two underlying standard Gaussian variables. These are chosen independent because of the approximately perpendicular structural conformation: $\mathrm{Y}_{1}$ that will be truncated by a threshold $\mathrm{t} 1$ distinguishing between facies $\mathrm{M}$ from other facies and $\mathrm{Y}_{2}$ to be truncated by other value of cut $t_{2}$ to discriminate the facies $L^{2}$ of the facies $\mathrm{S}$.

DESCRIPTION OF SAMPLED DATA A training image was digitized and turned into a matrix of discrete values and sampled at several scales constituting sampling groups for the several stages. So, one densely sampled file (100x 100) with a spacing of 10 pixels $(50 \mathrm{~m})$ will be used for variographic analysis intending to minimise the effects of an erroneous variogram fitting and a second one, used for the generation of the conditioning values, containing a smaller number of elements (36) with a spacing of 160 pixels $(800 \mathrm{~m})$.

This small amount of data points (Fig. 3A) in comparison with total area of $25 \mathrm{~km} 2$ gives a sample ratio is of 1.44 wells per $\mathrm{km}^{2}$, compatible with an appraisal stage in petroleum exploration. Note that the sample proportions (Fig. 3B) did not reproduce the global proportions very well, mainly the impermeable facies that in real data is $9 \%$ and here $5 / 36(13.9 \%)$. We decided to construct a proportion curve based on few sample data, getting the average of each of six rows of points (dotted points in Fig. 3C), filtering them with a moving average and then interpolating linearly. We can see in the dashed line the proportion curve based on exhaustive data set.

RELATIONSHIPBETWEEN INDICATORAND GAUSSIAN VARIOGRAMS The first key point of the plurigaussian technique is to provide Gaussian covariance models from indicator covariance models that are valid. The indicator variograms are obtained experimentally, but to get the covariance model of the underlying Gaussian variables, we have recourse to an iterative inversion approach of the relationships. It consists of arbitrating successive models for the two Gaussian variables and calculating the direct and cross variogram models of the indicator variables. Then we compare the calculated and the experimental indicator variograms, keeping the Gaussian models if a satisfactory fitting is obtained or guessing another otherwise.

The results of this operation are shown in Figure 4, in which are the direct and cross variograms of the facies $\mathrm{M}$ and $\mathrm{S}$ calculated along the main anisotropy directions (N45E and N45W) up to a distance equals to half of the image width. The modelling was performed through program INDVAR, provided by the Geostatistical Center of ENSMP for scientific purposes. The variograms of the two independent Gaussian variables, from which the indicator variograms have been calculated, are shown and tabled in Figure 5. The first of them $Y_{1}$ was used to model facies $M$ (tidal channels) and the second $\mathrm{Y}_{2}$ to discriminate between the facies $\mathrm{L}$ (shoreline) and $\mathrm{S}$ (impermeable facies). The variogram directions are $\mathrm{N} 45 \mathrm{E}$ and $\mathrm{N} 45 \mathrm{~W}$, approximately the same main anisotropy directions and the maximum distance is equals to half of the field.

GENERATIONOFGAUSSIANVALUESINDATAPOINTS The other key point is the generation of Gaussian values in data points that was obtained using a stochastic approach - the Gibbs sampler, as proposed by Le Loc'h \& Galli et al. (1997). The Gibbs sampler algorithm generates standard multigaussian values in an iterative 

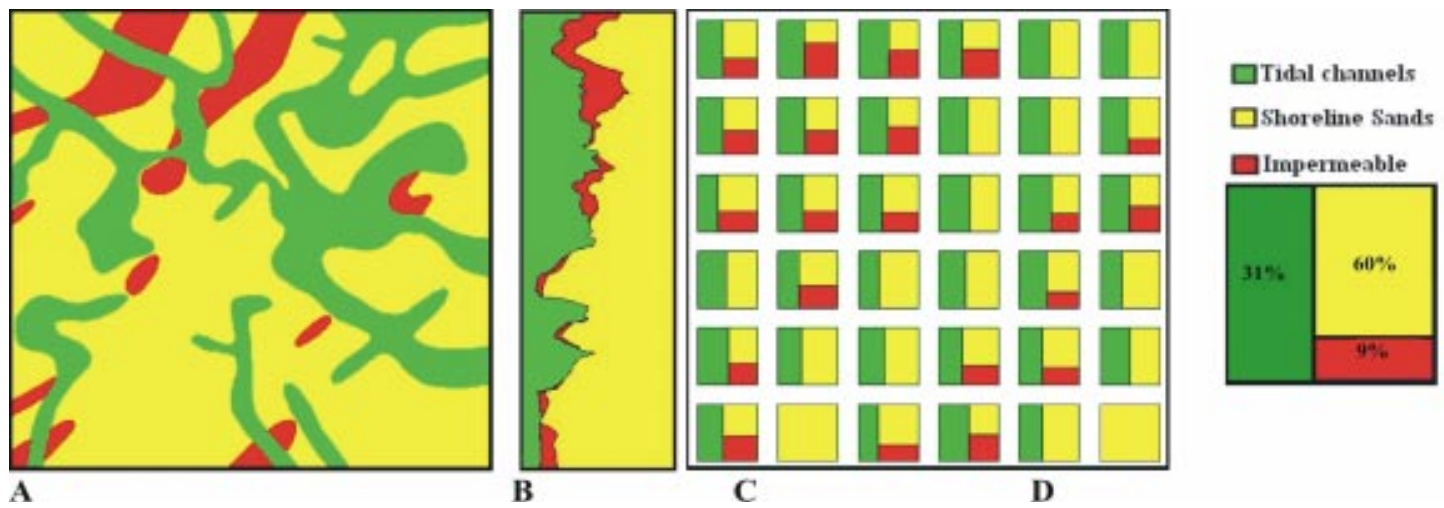

Figure $1-(\boldsymbol{A})$ Geological map; $(\boldsymbol{B})$ Proportion curves along NS direction; $(\boldsymbol{C})$ rock type rule with global proportions; $(\boldsymbol{D})$ proportion matrix.
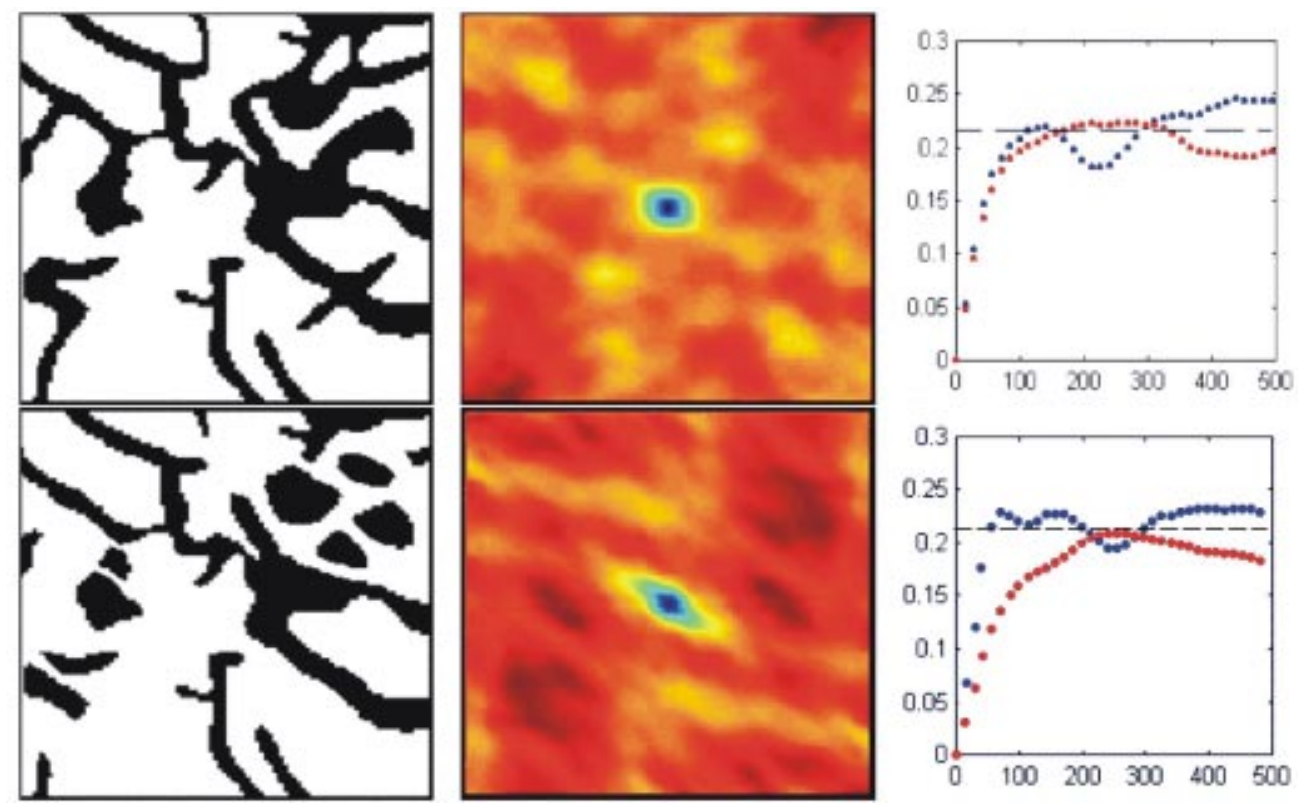

Figure 2 - (top) Indicator variable, variogram map and classical variogram for facies $M$ original; (bottom) Indicator variable, variogram map and classical variogram for reconstructed facies $M$.

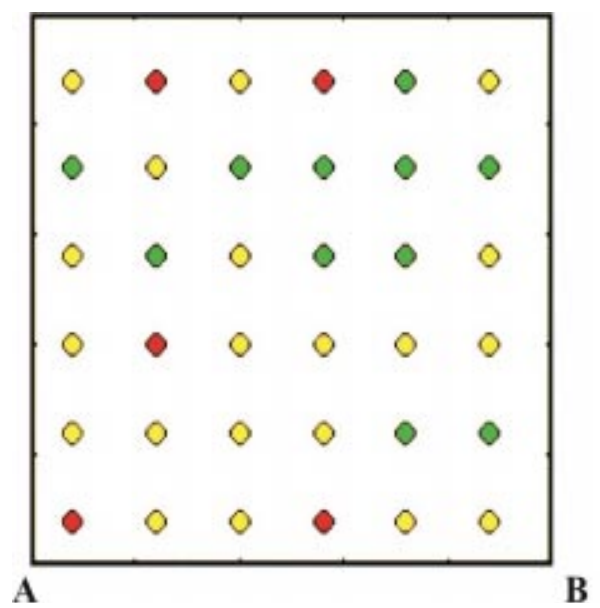

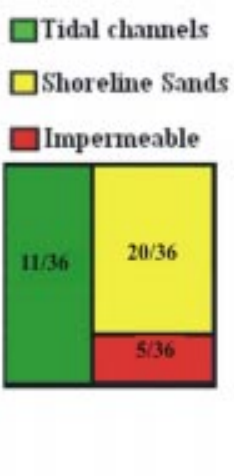

B
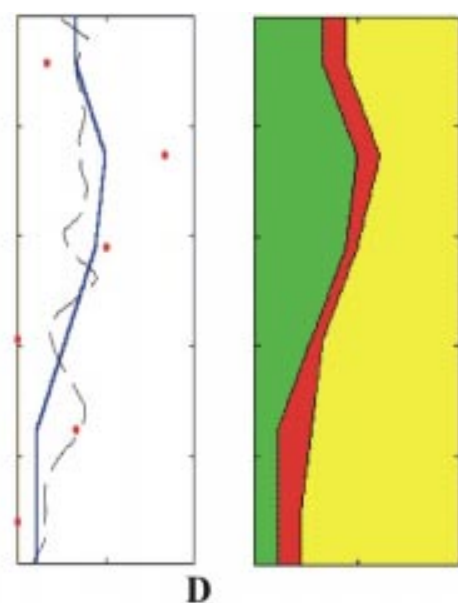

D

Figure 3 - (A) Location of data points; (B) rock type rule with sample proportions; $(C)$ treatment of curve proportion for tidal channel facies; $(D)$ proportion curve. 
Application of the plurigaussian simulation technique in reproducing lithofacies with double anisotropy
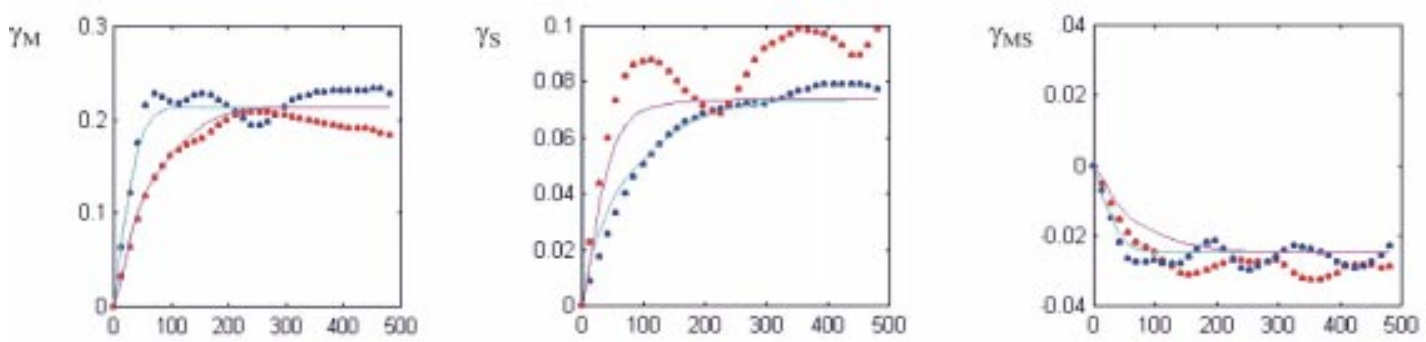

Figure 4 - Indicator variograms of facies M (left), L (center) and cross variogram (right) in directions N45E (blue) and N45W (red). Points show experimental data and lines show the modelled one.
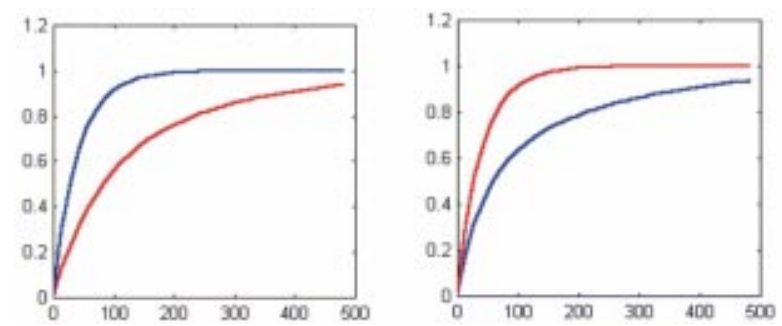

\begin{tabular}{|c|c|c|c|c|}
\hline variable & structure & sill & $\begin{array}{c}\text { N45E } \\
\text { range }\end{array}$ & $\begin{array}{c}\text { N45W } \\
\text { range }\end{array}$ \\
\hline \multirow{3}{*}{$\mathrm{Y}_{1}$} & Nugget & 0.01 & & \\
\cline { 2 - 5 } & Gaussian & 0.30 & 50 & 80 \\
\cline { 2 - 5 } & Gaussian & 0,69 & 80 & 250 \\
\hline \multirow{3}{*}{$\mathrm{Y}_{2}$} & Nugget & 0.01 & & \\
\cline { 2 - 5 } & Gaussian & 0.79 & 300 & 100 \\
\cline { 2 - 5 } & Gaussian & 0.20 & 360 & 120 \\
\hline
\end{tabular}

Figure 5 - Variograms along directions $N 45 E$ (blue) and $N 45 W($ red $)$ for the Gaussian variables $Y_{1}$ and $Y_{2}$ (left and center) and table of modelled parameters (right).
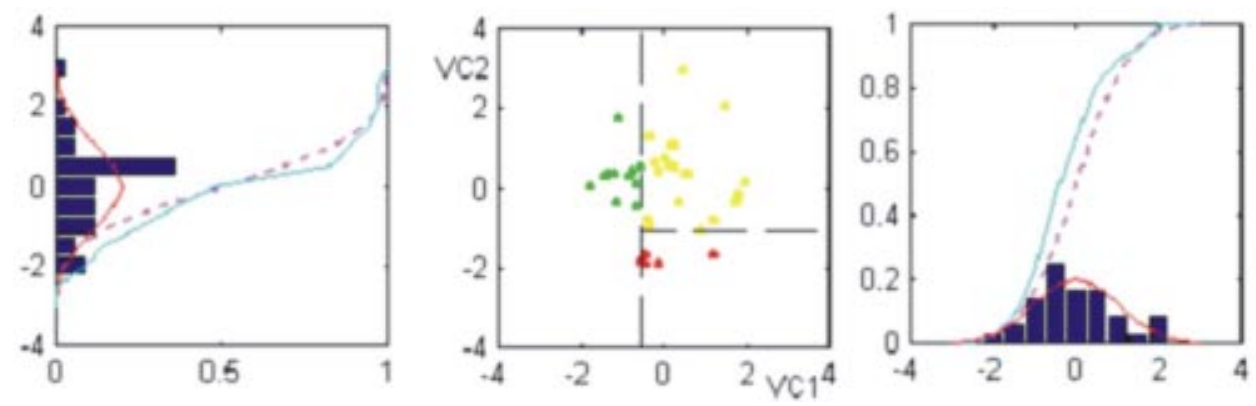

Data histogram

- Cumulative histogram

- Standard normal

-. Cumulative normal distr

- Tidal channels

Shoreline sands

- Impermeable

Figure 6 - Test of normality of the Gaussian values and obedience to thresholds in the stationary case.
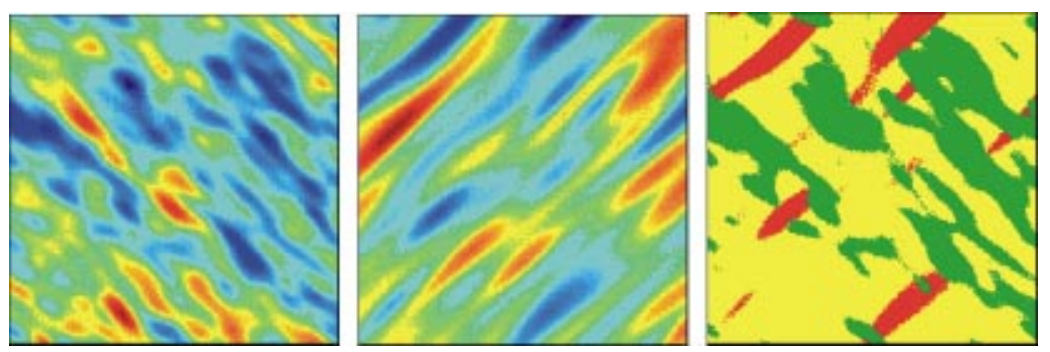

Figure 7 - Images of two simulated Gaussian functions $Y_{1}$ (left) and $Y_{2}$ (center) and composition of the truncated images according to the strategy (right).
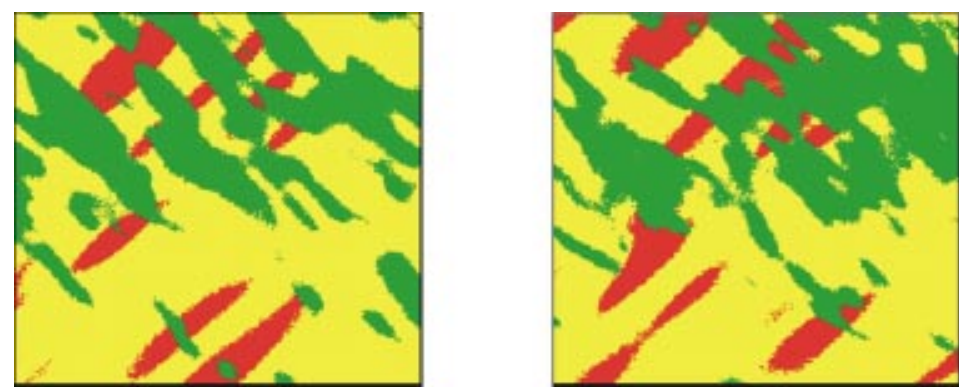

Figure 8 - Two simulated images: best one (left) and the worst one (right) according to the proportions. 
manner drawing random Gaussian values at experimental points; Kriging each point individually from the remainders using the previous covariance model; assigning a new value by adding the kriged value to a standard gaussian variable satisfying the thresholds.

We performed 500 iterations with the program CONDPTS, granted by the Geostatistics Centre of ENSMP for research purposes, to generate two populations of values that they were tested with respect to normality and obedience to the thresholds, as observed in the Figure 6.

CONDITIONALPLURIGAUSSIANSIMULATION Afterwe have gathered the covariances models and the conditioning points for the two Gaussian variables, the next step was to perform a classical conditional simulation that should be with either SGS or turning bands algorithm. We used the turning bands algorithm to simulate two Gaussian variables imaged in Figure 7 (left and center). Then we use the proportion curves of Figure 3D, converted to threshold curves, to truncate the Gaussian variables, obtaining the composition of right in in Figure 7 according to the strategy shown in Figure 3C.

RESULTANALYSIS We have generated a batch of 20 simulated images and analysed the statistical moments of first order, the proportions average. We can see in Table 1 interesting results, such as there is a reasonable difference between the proportions of the exhaustive and the sample data, mainly for facies $\mathrm{F}_{\mathrm{s}}$. This shows the importance and dependence of the simulations on the proportion curves.

We performed the same experiment, that is, we truncate the same Gaussian variables by stationary proportions from the samples, obtaining images whose proportions are closer to the sampled data proportions shown in gray in the table above.

The reproduction of the proportions is the first criterion for quality control and permits us to accept the batch of images to be analysed for other aspects. We chose arbitrarily the best and the worst images, from the point of view of the proportions (Fig. 8).

CONCLUSION Geostatistical methods have a large dependency on probabilistic models to face the amount of available data, so we can evaluate their hability when data is sparse. The earlier truncated Gaussian method is less effective on permitting to deal with geological information, but plurigaussian method can handle effectively with proportion curves, truncation strategy, multiple covariance models, etc. Proportion curves are very useful because they reflect the geological evolution of an area; truncation strategy (rock type rule) can deal properly with the transitions of facies and multiple covariance models could represent facies with different anisotropy axes. Plurigaussian simulation reveals to be a very interesting method but, nowadays, it relies hardly on an effective integration of geostatistical knowledge and geological experience.

Acknowlegements To the RBG referees for their sugestions to the manuscript.

Table 1 - Comparison between proportions obtained from exhaustive, sampled data and simulations.

\begin{tabular}{|c|c|c|c|c|}
\hline Set & Size $\backslash$ Proportions & $\mathrm{F}_{\mathrm{M}}$ & $\mathbf{F}_{\mathrm{S}}$ & $\mathbf{F}_{\mathrm{L}}$ \\
\hline Exhaustive data & 10000 pixels & $31.0 \%$ & $9.0 \%$ & $60.0 \%$ \\
\hline Sampled data & 36 pixels & $30.5 \%$ & $13.9 \%$ & $55.6 \%$ \\
\hline \multirow{2}{*}{$\begin{array}{c}\text { Proportion } \\
\text { curves }\end{array}$} & Average of 20 images & $32.1 \%$ & $9.7 \%$ & $58.2 \%$ \\
\cline { 2 - 5 } & Standard deviation & $1.6 \%$ & $1.1 \%$ & $1.9 \%$ \\
\hline \multirow{2}{*}{$\begin{array}{c}\text { Stationary } \\
\text { proportions }\end{array}$} & Average of 20 images & $30.5 \%$ & $13.2 \%$ & $56.2 \%$ \\
\cline { 2 - 5 } & Standard deviation & $1.0 \%$ & $1.2 \%$ & $1.4 \%$ \\
\hline
\end{tabular}

\section{References}

Armstrong M. \& Galli A. 1999. Derivative based plurigaussian simulations. In: S.J. Lippard, A. Naess \& R. Sinding-Larsen (eds), Trondheim-Norway, Proceedings of IAMG '99, 591-596.

Armstrong M., Eschard R, Galli A., Le Loc'h G. \& Roth C. 1998. Short course on plurigaussian simulations in mining and petroleum. Centre de Geostatistique, Fontainebleau - France, 45p.

Beucher H., Galli A., Le Loc'h G., Doligez B., Ravenne C. 1994. Including a regional trend in reservoir modelling using the truncated gaussian method. In: A. Soares (ed). Geostatistics Troia '92, Dordrecht, Kluwer Academic Press, 1:555-566.

Galli A., Beucher H., Le Loc'h G., Doligez B., Heresim Group. 1994. The pros and cons of the simulated Gaussian method. In: M. Armsstrong \& P.A. Dowd (eds) Geostatistical Simulations, Dordrecht, Kluwer Academic Press, 217-233.

Galli A. \& Beucher H. 1997. Stochastic models for reservoir characterization: a user-friendly review. In: SPE Latin America and Caribbean Petroleum Engineering Conference and Exhibition, 5, Rio de Janeiro-Brazil, Anais, SPE\#38999.

Le Loc'h G., Beucher H, Galli A, Doligez B., Heresim Group. 1994. Improvement in the truncated Gaussian method: combining several Gaussian functions. In: European Conference on the Mathematics of Oil Recovery, 4, Roros-Norway, 1994, 1-13.

Le Loc'h G. \& Galli A.. 1997. Truncated plurigaussian method: theoretical and practical points of view. In: E.Y. Baafi \& N.A. Schofield (eds) Geostatistics Wollongong '96, Dordrecht, Kluwer Academic Press, 1:211-222.

Matheron G., Beucher H, Fouquet, C., Galli A.., Guerrilot D. \& Ravenne C. 1987. Conditional simulation of the geometry of fluvio-deltaic reservoirs. In: SPE Annual Technical Conference and Exhibition, 62, Dallas-TX, 123-130, SPE \#16753 
Remacre A. Z. \& Simon V. H. 1998. Conditional plurigaussian simulation: a case study. In: Cahiers de Géostatistique, Compte rendu des Journées de Geostatistique, Fontainebleau - France, 6:17-28.

Roth C., Armstrong M, Galli A \& Le Loc'h G. 1998. Using plurigaussian simulations to reproduce lithofacies with contrasting anisotropies. In: APCOM Symposium, 27, London, Littleton-CO:SMME.

Simon V. H. 1997. Conditional truncated plurigaussian simulation. Instituto de Geociências, Universidade Estadual de Campinas, Tese de Mestrado, 85p.

Souza $\mathrm{Jr}^{\circ} \mathrm{G}$. 1997. Stratigraphie séquentielle et modélisation probabiliste des reservoirs d'un cone sous-marin profond (Champ de Namorado, Brésil), Université Paris 6, Paris, Doctoral thesis, 215 p.

Weimer P., Howard J. D., Lindsay D. R. 1982. Tidal flats and associated tidal channels. In: A. Sscholle \& D. Spearing (eds) Sandstone Depositional Environments. AAPG Memoir \#42, Tulsa-OK, 222245.

Zapparolli L.H. 2000. Application of plurigaussian simulation technique on reproducing lithofacies with double anisotropy. Faculdade de Engenharia Mecânica, Universidade Estadual de Campinas, Campinas, Tese de Mestrado, 128p.
Manuscrito SR-05

Recebido em 17 de novembro de 2002 Revisão dos autores em 01 de março de 2003 Revisão aceita em 30 de abril de 2003 